\title{
LA DEMOCRACIA DEL OCIO
}

Fausto Pretelin*

Es difícil reflexionar sobre democracia e instituciones en tiempos del gober precioso, uno de los políticos reconocido más por sus vicios privados que por sus virtudes públicas; en dónde encontrar el oxígeno que adormezca a la intranquilidad para que, de esta manera, pueda uno escuchar los balbuceos cavernarios de Emilio Gamboa Patrón recibiendo órdenes de su patrón, Kamel Nacif, personaje que en sus ratos libres se enreda en las telarañas más profundas de los sótanos de la pederastia; cómo entender al travestismo político de don Porfirio Muñoz Ledo, arquetipo bipolar del maximalismo ideológico y minimalismo ético; cómo comprender el sabático longevo de la presidencia de la República, seis años y la risa de Vicente Fox ya no provoca simpatía sino lástima por haber instaurado el sucedáneo de un sistema político, denominado democracia del ocio; en qué parte de las instituciones democráticas embona la presencia de Marta Sahagún; en qué momento Manuel Bartlett se sometió a una liposucción política con objeto de eliminar la grasa perversa acumulada en 1988 para transformarse en un niño héroe más de nuestro México; cómo interpretar los 49 días y 49 noches en que la estética de la avenida de la Reforma no transmitió más sentimientos que el de la impotencia de un berrinchudo; en qué piensa López Obrador cuando miente, sabe que miente y, por lo tanto, le cree a sus mentiras; en qué pensaría Luis Carlos Ugalde al no prepararse ante un escenario

\footnotetext{
* Departamento Académico de Estudios Internacionales, ITAM.
} 
hipotético que se convirtió en realidad la noche del 2 de julio; por qué razón los periodistas se convierten en paparazzis del más ignominioso mundo del espectáculo político; por qué razón la maestra Elba Esther representa, para los paparazzi, la modelo más sexy de la clase política; en dónde quedaron los 5 cuerpos de las correspondientes 5 cabezas que fueron abandonadas en la pista de baile del bar Luz y Sombra en Uruapan; cómo explicar las acciones de un grupo armado y pagado por Ricardo Salinas Pliego para amagar y desalojar a los trabajadores del canal 40 en el cerro del Chiquihuite y con ello, apropiarse de la pantalla; cómo un periodista de los autoimaginados héroes de la libertad de expresión, como Ciro Gómez Leyva puede introducir a la agenda política al esperpento del doctor Simi; sin confianza, cómo puede gobernar Ulises Ruiz en Oaxaca. Esto es México. El México de las simulaciones democráticas.

La palabra democracia, en México, es intangible. El peatón no la ve, no la siente. El automóvil lo atropella. Es la selva. La palabra democracia, en México, es polisémica. Muchos pero a la vez vacíos, sus significados. Las palabras pesan, huelen, viven. Ingresan en la cabeza de quien las escucha en forma de sonidos. Toman vida en

104 la pantalla del cerebro, se acumulan, posiblemente, en el alma. Pero en México, la palabra democracia pertenece a la naturaleza muerta o al mundo vivo de la ficción. El peatón de la historia la escucha pero no alcanza a experimentarla; intuye su significado pero se deprime al no poder encontrar la vitalidad de la misma, expresada en hechos, en instituciones funcionales. La palabra democracia la deletrea la simpática conductora de noticieros, la canta el político que se abstiene de mirarse ante el espejo demográfico pues de él emergen sus deformaciones ideológicas. Democracia, democracia, democracia. Ley, ley, ley. Ambas viven en el continente popular como entelequias; ambas son discrecionales; ambas son negociables.

La democracia, en México, como los árboles de navidad, es estacional. Aparece cada 6 años. Es tangible cuando el llamado ciudadano toma la boleta presidencial, la marca y la deposita en la urna. El color de la esperanza dibuja lo intangible. Pero siempre llegará el día des- 
pués. Regresa a su naturaleza muerta de la intangibilidad. Regresan los delegados para autorizar la construcción de pisos adicionales prohibidos por la ley; regresan las grúas que simulan recoger el desorden; regresa el presidente a su enternecedor hogar del nihilismo. Regresa la muerte de la imaginación.

¿Qué describe con atino a la realidad política mexicana? ¿La democracia o la anarquía institucionalizada y por lo tanto tolerable? Oximorones inimaginables en el país de las contradicciones sociales. El presidente que no gobierna; el payaso que comenta noticias; la botarga que sueña con la presidencia; la competencia entre partidos políticos que son iguales, pues en todos ellos aparece una raza de señores incultos que balbucean la voluntad de poder. Ha sido tan lasciva la devaluación de la palabra democracia, que ahora se rellena con eufemismos.

El año 2000 se convirtió en un momento refrescante. Llovieron expectativas. Supimos que los deseos podían ser realizables en el terreno de la política. Un fresco aire venció los muros de la indiferencia que identificaba a una gran parte de la sociedad. Como nunca antes se pensó en el futuro democrático. Por fin, la demografía se deslizaba a través de expectativas. Pero llegó Vicente Fox, un outsider que no supo interpretar el rompecabezas que le tocaba armar: negociación, cohabitación, tolerancia, transición y, sobre todo, imaginación, nunca fueron los rasgos de Vicente Fox. Para el pintor ruso Malevitch, los pintores deben rechazar los temas y los objetos, si quieren ser pintores puros. Cuando la conciencia haya perdido la costumbre de ver en el cuadro la representación de rincones de la naturaleza, de madonas y de Venus impúdicas, veremos la obra puramente pictórica. Fox no pudo ver más allá del paisaje cotidiano. Sus decisiones fueron inerciales y nunca imaginativas; su figura fue arrastrada por la corriente brutal del río de la cotidianidad. No excitó cambios. Su virtud involuntaria tiene que ver con la ingravidez presidencial. Pero al ser involuntaria no logró institucionalizarla. Es decir, en este país todos los políticos desean la presidencia. Presidentes municipales, diputados, senadores, meseros, cuenta chistes. La figura presidencial sigue representando la droga para 
la todavía concupiscente clase política. La espiral toca a la sociedad quien en su mayoría, le es indiferente lo que haga o deje de hacer un diputado.

Fox institucionalizó la mercadotecnia como pastilla milagrosa de su sexenio. Encuestas, consultores de imagen, medidores emocionales, spots ilusionistas, zapping mental. Segmentó el mercado entre círculos cerebrales rojos y verdosos óvalos despolitizados. Optó por desarrollar estrategias de comunicación con los segundos. Eligió desmontar puentes con los primeros. Su campaña presidencial fue imaginativa y exitosa porque gran parte de la sociedad quería ver al hombre desenfadado que martirizara a un PRI debilitado como el puntillero que corta la agonía del toro al atravesarle el cerebro con un hierro. Pensó que el gobierno sería una extensión de la campaña y al hacerlo se mimetizó. Al Estado nunca lo conoció. Al gobierno lo interpretó como un parque temático cuya única misión era entretener a los visitantes, es decir, a los ciudadanos. Siguió las recetas milagrosas de Paolo Coelho y Dan Brown. Las leyes inmutables del parque temático de la política son claras. Estos fueron algunos de sus juegos:

- Habla al corazón de las personas.

- Arremángate las mangas de la camisa.

- Lleva siempre contigo una laptop. Eres moderno. (No le hagas caso a Roland Barthes cuando escribió, "de repente, se me ha vuelto indiferente no ser moderno".)

- La dictadura de la imagen convence y coacciona. Disipa dudas.

- La competencia se desarrolla en la mente del consumidor. Por ello, lo in son las entelequias.

- Evita el divorcio entre lo políticamente correcto con el conservadurismo de la sociedad mexicana.

- ¡Házte a la idea de que eres López Dóriga! Tienes que informar a la sociedad.

- ¡Házte a la idea de que tú puedes llegar a ser un líder de opinión!

- No es la publicidad la que imita a la vida, es la vida la que imita a la publicidad. Por lo tanto, el 2 de julio se votó por el mejor spot no 
por un cuerpo ideológico institucionalizado en un partido político y encarnado por un candidato.

- La banalidad se ha convertido en un artículo de lujo y se demanda a precios asequibles por todos los integrantes de la masa.

- La imagen es la forma de comunicación más poderosa que existe.

- Leer periódicos no es un acto de moda.

- Un spot de Chanel o Luis Vuitton de 30 segundos son más eficientes que 60 minutos de un debate al que no acude López Obrador.

- La izquierda y la derecha no existen. Existe el centro. Desde allí se ganan las elecciones.

Es probable que Vicente Fox presidente haya quedado atrapado por Vicente Fox candidato; cuando tuvo que formar gobierno se desmoronó su ruta hacia lo que él pensaba sería el éxito. El Vicente Fox presidente ridiculizó al Vicente Fox candidato. No pudo percatarse de que una campaña política la puede ganar un gran animador pero una buena presidencia se gana con la generación de la materia prima cuya escasez preocupa y se resiente día a día, la confianza.

Las leyes inmutables atraparon al presidente. Todo se convirtió en el primer parque temático nihilista-surrealista del mundo. La metáfora de los head hunters se presentó como escenografía de los patos que conversaron con Cerisola para convencerlo de que no construyera un aeropuerto; con Derbez para erosionar las relaciones de México con más de una nación; la educación en manos de Reyes Tamez se fue de vacaciones; Abascal nunca entendió la laicidad. Muchos de los secretarios solamente los conocimos por medio de spots que competían contra la seducción que despierta un perfume o la frescura que obsequia una bebida. Muchos de ellos murieron gracias al zapping.

Por lo anterior, no era difícil pensar que las elecciones del pasado 2 de julio las ganaría el PRD. Sin embargo, la posibilidad de una izquierda progresista nunca se presentó como escenario. Como sucedió durante el siglo pasado, la izquierda se dejó seducir por el neocaudi1lismo, es decir, por el político-inmediático. Rapidez y presencia en los medios desde las seis de la mañana. Él impuso durante 5 años la agenda política. Los feligreses, hipnotizados por el romanticismo, 
durmieron. Y cuando despertaron se encontraron en un país llamado Fanatisland, es decir, la isla del fanático. No se equivocó Albert Camus al señalar que el peor enemigo de la inteligencia es el fanatismo. López Obrador se convirtió en su propio héroe; desprendió de él a un ser a quien le fue devoto; generó un catecismo alrededor de su figura. Su principal virtud, el instinto, fue eclipsado por la soberbia. Con soberbia, López Obrador se mofó de un auditorio al ausentarse del debate; con soberbia mintió con su ya famosa encuesta misteriosa en la que ganaría por 10 puntos porcentuales; fue la soberbia la que le impidió ver a los enemigos en casa: los equilibristas de la política como Camacho, Ebrard y Arreola; los que gestionan al gobierno desde el CGH como Batres, Fernández Noroña, Padierna.

México es un país cuya base demográfica son los jóvenes. El discurso hipnótico de López Obrador miró hacia el pasado. Cuando lo que apremia a la juventud es el futuro. Charles Perrault escribió:

La hermosa Antigüedad fue siempre venerable

Pero no he creído nunca que también fuera adorable

Contemplo a los Antiguos sin ponerme de rodillas.

Son grandes, es cierto, pero hombres como nosotros

La noche del 2 de julio del presente año López Obrador inició el final de su carrera política. La oficializó el día que cerró Paseo de la Reforma. Pero también Vicente Fox, como Calderón, Ugalde y una importante parte de los medios de comunicación agredieron a la incipiente democracia. En resumen, todos perdieron. Todos perdimos.

Del embrollo heredado por las lecciones del 2 de julio se desprende lo siguiente:

- En la mayoría de los actores políticos no hay cultura democrática.

- Nos encontramos aún en plena transición democrática, sin embargo, la dirección es muy ambigua.

- Hay alternabilidad pero no confianza en los partidos políticos.

- Los diputados y senadores no tienen protagonismo autónomo, son guiados por paradigmas. 
- La negociación no es un código lingüístico democrático.

- El IFE no soportó las presiones generadas a partir del estrecho margen entre Felipe Calderón y López Obrador.

- El presidente Fox no actuó como jefe de Estado durante el proceso electoral y, como jefe de gobierno, durante los seis años su liderazgo fue menguado.

- $\quad$ El PRD quedó rebasado por el protagonismo de López Obrador.

- López Obrador evitó la rendición de cuentas hacia sus seguidores por medio del engaño.

- La distancia entre los políticos y los ciudadanos creció más.

- La confianza es inexistente.

- Los medios de comunicación tienen más poder que los propios políticos.

- La publicidad ocupa peligrosamente un protagonismo en la vida política del país. 
CITAM Derechos Reservados.

La reproducción total o parcial de este artículo se podrá hacer si el ITAM otorga la autorización previamente por escrito. 